\title{
COMPARATIVE STUDY BETWEEN ENDOSCOPIC TRANSCANAL MYRINGOPLASTY VERSUS MICROSCOPIC MYRINGOPLASTY IN MIDDLE AGE GROUP (20-40 YEARS)
}

\author{
By
Hossam Mohammed Esam ,Wael Hassan Abo El-Wafa and Mohammed Kamel Ibrahem Al-Awady \\ Department of Otorhinolaryngology, Faculty of Medicine, Al-Azhar University
}

\begin{abstract}
Background: Myringoplasty (tympanoplasty type I) is usually the treatment of choice for tympanic perforations, whether or not associated with non-suppurative chronic otitis media.

Objective: To determine the advantages and disadvantages of endoscopic as compared to microscopic myringoplasty surgery and to compare the results of both groups.

Patients and methods: This study was carried out at the Otorhinolaryngology Department, Al-Azhar University Hospitals. The study included 40 patients. The age of all patients was between $20-40$ years old with a diagnosis of chronic suppurative otitis media of tubo-tympanic type, divided into two equal groups.

Results: The difference in age, gender, side of diseased ear and size of perforation between the two groups was not significant. In group (A) the circumference of the perforation was clearly visualized in all patients, while in group (B) the circumference of the perforation could not be visualized in 35\% of patients. $25 \%$ required external auditory canal curettage and $10 \%$ required endoscope assisted microscopic myringoplasty to evaluate the ossicular chain. The difference between the 2 groups was significant. The graft was obtained from the tragal cartilage. In endoscopic group, the graft was uptaken in $85 \%$ of patients, while in microscopic group the graft was uptaken in $80 \%$ of patients with no statistical significant difference between the two groups.

Conclusion: Comparison of microscopic and endoscopic views revealed superior visualization of the endoscopic approach as opposed to microscopic myringoplasty as endoscopic myringoplasty can be performed, regardless of the perforation size and the narrowness and/or protrusion of external ear canal. So, external auditory canal curettage and canalplasty can be avoided in endoscopic technique.
\end{abstract}

Key words: Myringoplasty, endoscopic, microscopic.

\section{INTRODUCTION}

Myringoplasty (tympanoplasty type I) is usually the treatment of choice for tympanic perforations, whether or not associated with non-suppurative chronic otitis media (Tawab et al., 2014). The surgical goal is the total closure of the perforation and secondly, an improvement of auditory thresholds (Hong et al., 2013).
In the last decade, there has been an increase in the use of endoscopes in otologic surgery, not just as an adjunct method, but exclusively (Ayache, 2013).

Though endoscopes were mainly introduced for sino nasal surgeries, its use is no more restricted to nasal surgeries with surgeons using the scopeto access 


\section{Hossam Mohammed Esam - et al.,}

other areas like ear, larynx, skull base (Mohindra and Panda, 2010).

The use of a rigid endoscope for myringoplasty has a significant advantage as it is simple to use, not only for the examination, but also for the repair of the tympanic membrane perforation. This provides a magnified vision and hence enables the surgeon to change rapidly from a close-up to a wide angle view, just by going closer or by withdrawing the scope. Further, it provides an all-round vision to the surgeon, who can rotate the angled endoscope to visualise the deep anterior canal wall, anterior recess, anterior marginal perforations, sinus tympani, fascial recess, hypotympanum and the attic (Patil et al., 2015).

The view during microscopic surgery is defined and limited by the narrowest segment of the ear canal, whereas transcanal endoscopy bypasses the narrowest ear canal and provides a wider view, even when a $0^{\circ}$ endoscope is used (Tarabichi et al., 2013).

The present work aimed to compare between edoscopic and microscopic myringoplasty.

\section{PATIENTS AND METHODS}

This study was carried out at the Otorhinolaryngology Department, AlHussin and Bab-Alsharia University hospitals. The study included 40 patients. The age of all patients was between 20 40 years old with a diagnosis of chronic suppurative otitis media of tubo-tympanic type, divided into two equal groups:

Group A were operated using the endoscope-assisted myringoplasty.
Group B were operated using microscopic myringoplasty.

All patients have given informed written consents.

\section{Inclusion Criteria:}

1. Patients having small, medium and large (subtotal) dry perforation of tympanic membrane.

2. Patients having chronic suppurative otitis media of tubo-tympanic type.

3. No evidence of infection in nose, paranasal sinuses, nasopharynx and throat.

4. Traumatic perforation.

\section{Exclusion criteria:}

1. Patients less than 20 years old or more than 40 years old.

2. Infected ears.

3. Revision Myringoplasty.

4. Patients with chronic suppurative otitis media of attico-antral type (cholesteatoma).

5. Patients with complications of chronic otitis media.

6. Patients with chronic medical diseases as diabetes mellitus, chronic renal or hepatic diseases.

\section{Preoperative assessment:}

1. Thorough history taking.

2. Full ENT examination.

3. Hematological investigations (bleeding time, platelet count).

4. Pure tone audiometry.

Patients were discharged on the same day of the surgery. All patients received postoperative antibiotics for at least 7 days 
after surgery. Patients were instructed to avoid wetting of the ears, sneezing, constipation and vigorous blowing of the nose.

Postoperative follow-up was performed for at least 2 months. The first postoperative visit was after one week for removal of aural pack and stitches after which antibiotic ear drops were prescribed for one week. Follow up included otoscopic examination of the TM to monitor graft healing. Audio logical assessment (PTA) was done at the end of the second month postoperatively.

In microscopic group, five patients required external auditory canal curettage and 2 patients required using endoscope to assist the microscope in visualization of the edges of the perforation while in endoscopic group no such procedures were needed.

\section{Statistical analysis:}

Recorded data were analyzed using the statistical package for social sciences, version 20.0 (SPSS Inc., Chicago, Illinois, USA). Quantitative data were expressed as mean \pm standard deviation (SD) and range. Qualitative data were expressed as frequency and percentage. The following tests were done:

- Independent-samples t-test of significance was used when comparing between two means.

- Paired sample t-test of significance was used when comparing between related samples.

- Analysis of non-parametric data by Mann-Whitney test displayed as median, interquartile range, minimum and maximum.

- Chi-square $\left(\mathrm{x}^{2}\right)$ test of significance was used in order to compare proportions between qualitative parameters.

- The confidence interval was set to $95 \%$ and the margin of error accepted was set to $5 \%$. P-value was considered significant when it was $<0.05$.

\section{RESULTS}

The study was done from March 2018 to May 2019. The age of the patients ranged from 20 to 40 years old in all cases, with mean of 31.40 years and standard deviation of 5.95 in group A \& mean of 31.85 and standard deviation of 5.76 in group B. There was no significant difference between the two groups regarding the age distribution.

In endoscopic group (group A): males represented $70 \%$ (14 cases) and females represented $30 \%$ (6 cases) while in microscopic group (group B): males represented $45 \%$ (9 cases) and females represented $55 \%$ (11 cases). The difference in gender between the patients was not significant ( $\mathrm{P}$ value 0.11 ).

In group (A), the size of perforation was large (subtotal) in 10 patients $(50 \%)$, medium sized in 6 patients $(30 \%)$ and small in 4 patients $(20 \%)$. Meanwhile in group (B), the perforation was large (subtotal) in 12 patients $(60 \%)$, medium sized in 4 patients $(20 \%)$ and small in 4 


\section{Hossam Mohammed Esam - et al.,}

patients $(20 \%)$. The difference in size of perforation distribution between the two

groups was not statistically significant (Table 1).

Table (1): Distribution of patients with respect to age, gender, side and size of perforation in the study groups

\begin{tabular}{|c|c|c|c|}
\hline $\begin{array}{ll}\text { Parameters } & \text { Groups } \\
\end{array}$ & $\begin{array}{c}\text { Group A } \\
\mathbf{N}=20\end{array}$ & $\begin{array}{c}\text { Group B } \\
\mathbf{N}=20\end{array}$ & P-value \\
\hline $\begin{array}{l}\text { Age in years } \\
\text { Mean } \pm \text { SD }\end{array}$ & $31.40 \pm 5.95$ & $31.85 \pm 5.76$ & 0.809 \\
\hline $\begin{array}{l}\text { Gender: n (\%) } \\
\text { Males }\end{array}$ & $14(70 \%)$ & $9(45 \%)$ & \multirow[t]{2}{*}{0.110} \\
\hline Females & $6(30 \%)$ & $11(55 \%)$ & \\
\hline $\begin{array}{l}\text { Side of diseased ear } \\
\text { Right }\end{array}$ & $12(60 \%)$ & $9(45 \%)$ & \multirow[t]{2}{*}{0.342} \\
\hline Left & $8(40 \%)$ & $11(55 \%)$ & \\
\hline $\begin{array}{l}\text { Size of perforation } \\
\text { Large (subtotal) }\end{array}$ & $10(50 \%)$ & $12(60 \%)$ & 0.525 \\
\hline Medium & $6(30 \%)$ & $4(20 \%)$ & 0.465 \\
\hline Small & $4(20 \%)$ & $4(20 \%)$ & 1.000 \\
\hline
\end{tabular}

In group (A) the circumference of the perforation was clearly visualized in all patients $(100 \%)$ even when the ear canal was narrow or protruding and in patients with subtotal perforation without need for external auditory canal curettage or canaloplasty. While in group (B) the circumference of the perforation could not be visualized in 7 patients $(35 \%), 5$ patients $(25 \%)$ required external auditory canal curettage and 2 patients (10\%) required microscopic myringoplasty assisted by endoscope to evaluate the ossicular chain.

The difference between the 2 groups was significant (Table 2).

Table(2): Visualization of the edges of the perforation

\begin{tabular}{|l|c|c|c|}
\hline \multicolumn{1}{|l|}{ Groups } \\
$\begin{array}{l}\text { Visualization } \\
\text { of the edges of } \\
\text { the perforations: } \mathbf{n}(\%)\end{array}$ & $\begin{array}{c}\text { Group A } \\
\mathrm{N}=20\end{array}$ & $\begin{array}{c}\text { Group B } \\
\mathrm{N}-20\end{array}$ & P-value \\
\hline Visualized & $20(100 \%)$ & $13(65 \%)$ & \multirow{2}{*}{0.004} \\
\hline Could not be visualized & $0(0 \%)$ & $7(35 \%)$ & \\
\hline Added procedures & $0(0 \%)$ & $5(25 \%)$ & 0.017 \\
\hline Curettage & $0(0 \%)$ & $2(10 \%)$ & 0.147 \\
\hline Microscope assisted by endoscope
\end{tabular}

No statistically significant difference between both groups according to air bone gap (ABG) preoperatively and after 2 months postoperatively (Table 3). 
Table(3): ABG of the studied groups:

\begin{tabular}{|c|c|c|c|}
\hline Groups & $\begin{array}{c}\text { Group A } \\
\mathbf{N = 2 0}\end{array}$ & $\begin{array}{c}\text { Group B } \\
\text { N=20 }\end{array}$ & P-value \\
\hline $\begin{array}{c}\text { Preoperative ABG: } \\
\text { mean } \mathbf{n} \text { SD }\end{array}$ & $22.85 \pm 3.34$ & $23.75 \pm 2.90$ & 0.369 \\
\hline $\begin{array}{c}\text { Postoperative ABG: } \\
\text { median (IQR) } \\
\text { min-max }\end{array}$ & $\begin{array}{c}12.5(10-16.75) \\
0-27\end{array}$ & $\begin{array}{c}14(10-16.5) \\
0-26\end{array}$ & 0.714 \\
\hline $\begin{array}{c}\text { ABG gain: median } \\
\text { (IQR) }\end{array}$ & $8(6.25-13.75)$ & $11(6.75-12)$ & 0.718 \\
min-max & $1-17$ & $1-19$ & 0.829 \\
\hline $\begin{array}{c}\text { ABG gain percent: } \\
\text { median (IQR) } \\
\text { min-max }\end{array}$ & $\begin{array}{c}42.7(27.89-57.38) \\
3.57-100\end{array}$ & $\begin{array}{c}46.99(28.94-54) \\
4.17-100\end{array}$ & \\
\hline \multicolumn{2}{|c|}{} & & \\
\hline
\end{tabular}

In endoscopic group the graft was up taken in $85 \%$ of patients (17 patients) and not taken in $15 \%$ of patients ( 3 patients) while in microscopic group the graft was up taken in $80 \%$ of patients (16 patients) and not taken in $20 \%$ of patients (4 patients). There were no significant statistical difference between the two groups $(\mathrm{p}=0.677)($ Table 4).

Table (4): Graft taking of the studied groups

\begin{tabular}{|c|c|c|c|}
\hline Graft taking & $\begin{array}{c}\text { Group A } \\
\text { N (\%) }\end{array}$ & $\begin{array}{c}\text { Group B } \\
\text { N (\%) }\end{array}$ & \multirow{2}{*}{} \\
\cline { 1 - 3 } Taken & $17(85 \%)$ & $16(80 \%)$ & \multirow{2}{*}{0.677} \\
\hline Not taken & $3(15 \%)$ & $4(20 \%)$ & \\
\hline
\end{tabular}

Regarding complications, there were 3 residual perforations in endoscopic group $(15 \%)$ and another 4 residual perforations in microscopic group $(20 \%)$. All presented with post- operative infection and irregular follow up. No other complications reported as SNHL in both groups. So there was no statistically significant difference regarding complications between endoscopic and microscopic groups after 2 months postoperatively (Table 5).

Table (5): Complications among the study groups after 2 months postoperatively

\begin{tabular}{|c|c|c|}
\hline Complications & $\begin{array}{c}\text { Groups } \\
\text { N. 20 }\end{array}$ & $\begin{array}{c}\text { Microscopic group } \\
\text { N. 20 }\end{array}$ \\
\hline Residual perforation & $3(15 \%)$ & $4(20 \%)$ \\
\hline SNHL & 0 & 0 \\
\hline
\end{tabular}

\section{DISCUSSION}

Different endoscopes have been used in the performance of ear surgery in general and myringoplasty in particular, and the surgical success of endoscope- assisted tympanoplasty ranges between 80 and 100\% (Dündar et al., 2014).

This study was carried out at ENT Department, Al Hussin and Bab Al-Sheria University hospitals on patients with a 


\section{Hossam Mohammed Esam - et al.,}

diagnosis of chronic otitis media or with traumatic perforations without spontaneous resolution for more than three months prepared for myringoplasty. The aim was to evaluate and compare the advantages, disadvantages and outcomes of endoscopic transcanal myringoplasty as compared to microscopic myringoplasty.

In group (A), the circumference of the perforation was clearly visualized in all patients $(100 \%)$ without need for external auditory canal curettage or canaloplasty, while in group (B) the circumference of the perforation could not be visualized in 7 patients $(35 \%), 5$ patients $(25 \%)$ required external auditory canal curettage and 2 patients (10\%) required microscopic myringoplasty assisted by endoscope to evaluate the ossicular chain. So, there were statistical significant differences between the 2 groups.

In this study, endoscope gave good exposure to the perforation and the middle ear which was similar to observation of Lade et al. (2014). Also, Migirov and Wolf (2015) stated that the transcanal microscope-assisted endoscopic myringoplasty had a $100 \%$ rate of surgical success. They mentioned that this technique can be especially appropriate for patients with narrow external canals, anterior defects and bone overhang making the perforation margins barely visible under a microscope.

Furukawa et al. (2014) mentioned that the circumference of the perforation could not be confirmed with a microscope before denuding in $12.0 \%$ of cases. Furthermore, the entire perforation was not visible in $20.0 \%$ of cases after refreshing the edges. In contrast, endoscopy can show the entire tympanic membrane in one field with clear visualization of the perforation edges, even when the ear canal is narrow or protruding.

In this study, the graft was up taken in $85 \%$ of patients and not taken in $15 \%$ of patients in group (A), while the graft up taken in $80 \%$ of patients and not taken in $20 \%$ of patients in group (B). The improvement in the A-B gap showed no significant difference between the two groups.

The present results were in line with those of Furukawa et al. (2014) who reported a perforation closure rate of $84.0 \%$ and the improvement in ABG was $10.3 \mathrm{~dB}$ in transcanal endoscopic myringoplasty. Ayache (2013) reported that using cartilage grafts in patients undergoing endoscopic tympanoplasty can achieve a success rate of $96 \%$. With the increasing use of minimally invasive surgery, using an endoscopic approach could fulfill the goal of causing the least amount of trauma to normal tissues (Ö̈gür et al., 2015).

According to this study, the disadvantage of the endoscope is a one handed technique. Surgeon has to hold the scope in one hand during all the time while only other hand is free to operate. It was consistent with study of Patel et al. (2015) also reported that the major disadvantage of endoscopic approach was the necessity to operate with a single hand. They also stated that any bleeding in the external ear canal made manipulations very difficult and underlined the necessity to achieve total hemostasis in the external ear canal.

In our study, endoscopes allowed us close inspection of the tympanic 
membrane perforation, the drum remnant, the eustachian tube orifice, the middle ear mucosa and ossicular chain. The anatomical variations (tortuous or stenotic ear canal, anterior meatal overhang etc.) that hamper the view of entire tympanic membrane during ear surgery were overcomed by the use of endoscopes. Endoscope holds the greatest promise in ear surgery in coming days (Lakpathi and Reddy 2016).

\section{CONCLUSION}

Comparison of microscopic and endoscopic views revealed superior visualization of the endoscopic approach as opposed to microscopic myringoplasty as endoscopic myringoplasty can be performed, regardless of the perforation size and the narrowness and/or protrusion of external ear canal. So, external auditory canal curettage and canalplasty can be avoided in endoscopic technique. Thus, endoscopic transcanal myringoplasty can be a good alternative of microscopic myringoplasty.

\section{REFERENCES}

1. Ayache S (2013): cartilaginous myringoplasty: the endoscopic transcanal procedure. Eur Arch Otorhinolaryngol., 270: $853-60$.

2. Dündar R, Kulduk E, Soy FK, Aslan M, Hanci D and Muluk NB (2014): Endoscopic versus microscopic approach to type 1 tympanoplasty in children. Int $\mathrm{J}$ Pediatr Otorhinolaryngol., 78: 1084-1089.

3. Furukawa T, Watanabe T, Ito T, Kubota $T$ and Kakehata $S$ (2014): Feasibility and advantages of transcanal endoscopic myringoplasty. Otol Neurotol., 35: e140-5.

4. Hong $P$, Bance $M$ and Gratzer PF (2013): Repair of tympanic membrane perforation using novel adjuvant therapies: a contemporary review of experimental and tissue engineering studies. Int $\mathbf{J}$ Pediatr Otorhinolaryngol., 77:3-12.

5. Lade H, Choudhary SR and Vashishth A. (2014): Endoscopic vs. microscopic myringoplasty: a different perspective. Eur Arch Otorhinolaryngol., 271: 1897-1902.

6. Lakpathi G and Reddy LS (2016): Comparative study of endoscope assisted myringoplasty and microscopic myringoplasty. Indian JOtolaryngol Head Neck Surg., 68:185-191.

7. Migirov $L$ and Wolf $M$ (2015): Transcanal microscope-assisted endoscopic myringoplasty in children. BMC Pediatrics, 15:32-35.

8. Mohindra S and Panda NK (2010): Ear surgery without microscope;is it possible. Indian J Otolaryngol Head Neck Surg., 62(2):138-141.

9. Özgür, A., Dursun, E., Erdivanli, Ö. Ç., Coşkun, Z. Ö., Terzi, S., Emiroğlu, G. Ö. K. H. A. N. and Demirci, M. (2015): Endoscopic cartilage tympanoplasty in chronic otitis media. The Journal of Laryngology \& Otology., 129(11): 10731077.

10. Patel J, Aiyer RG, Gajjar Y, Gupta R, Raval J and Suthar PP (2015): Endoscopic tympanoplasty vs. microscopic tympanoplasty intubotympanic CSOM: a comparative study of 44 cases. Int J ResMed Sci., 3(8):1953-1957.

11. Tarabichi M, Ayache S, Nogueira JF, Al Qahtani $M$ and Pothier DD (2013): Endoscopic management of chronic otitis media and tympanoplasty. Otolaryngol Clin North Am., 46:155-163.

12. Tawab A, Gharib F, EISharkawy $L$ and Algarf T (2014): Myringoplasty with and without cortical mastoidectomy in treatment of non-cholesteatomatous chronic otitis media: acomparative study. Clin Med Insights Ear Nose Throat, 7:19-23. 
Hossam Mohammed Esam - et al.,

\section{دراسة مقارنة بين عملية ترقيع طبلة الأذن باستخدام

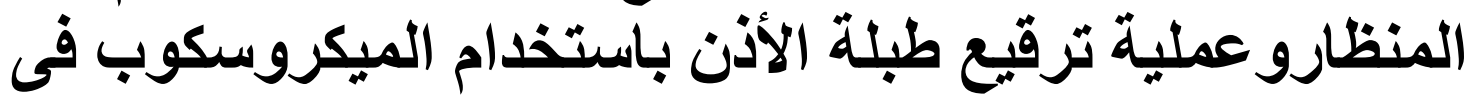 المرضى متوسطى العمر (20-40 سنة بالة)}

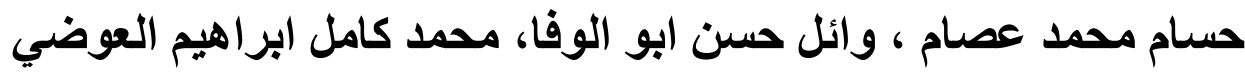

قسم الانف والاذن والحنجرة، كلية طب الأزهر

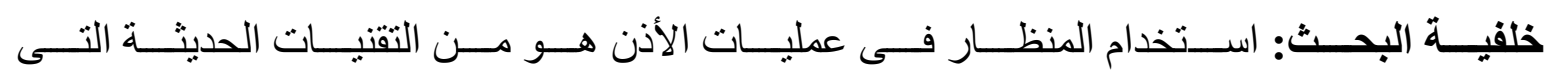

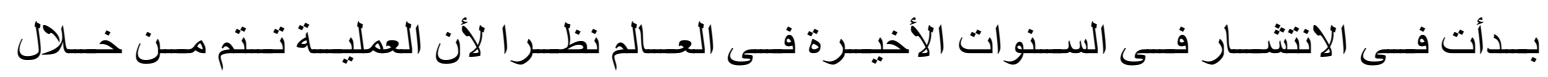

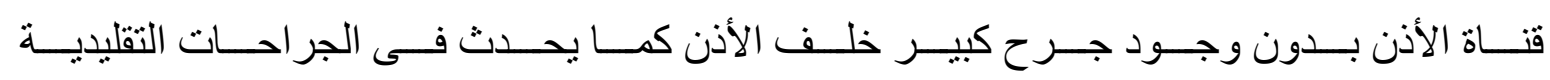

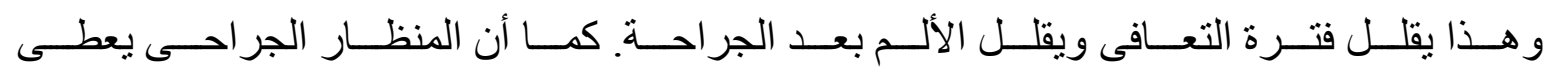
تفاصيل دقيقة أثناء الجر احة لا يوفر ها الميكروسكوب.

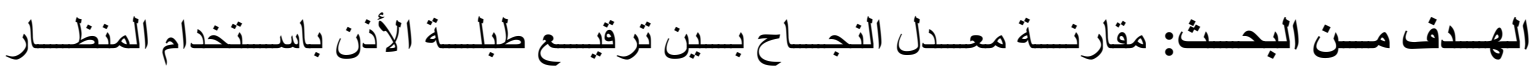

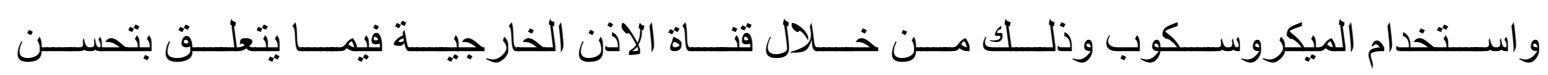

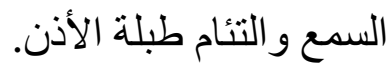

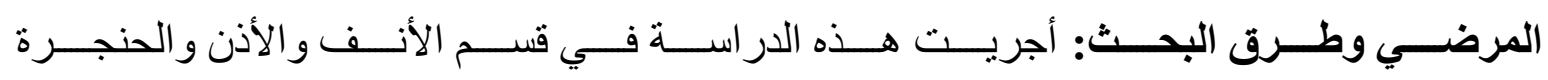

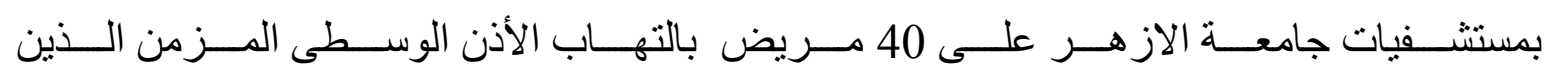

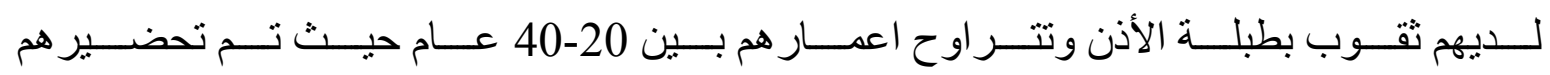
لجر احة ترقيع طبلة الاذن.

وقد تم تقسيم المرضي الي مجموعتين متساويتين:

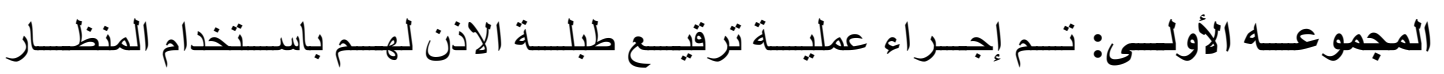

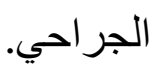

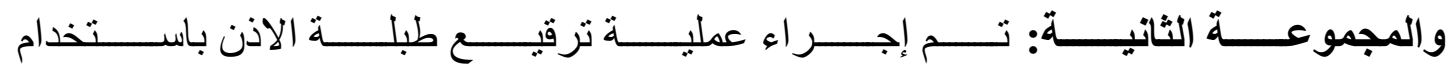
الميكروسكوب. 


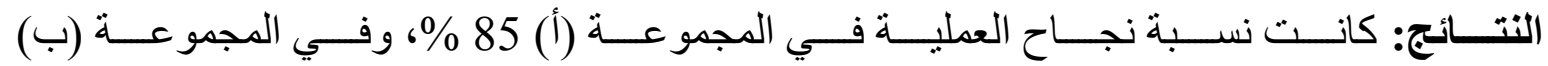

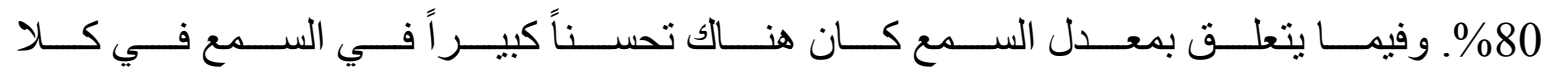
المجمو عتين، ولكن لم يكن هنالك فرقاً احصائياً ما بين المجمو عتين.

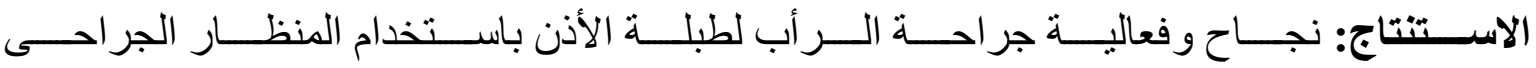

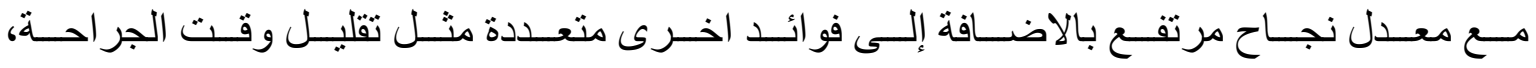

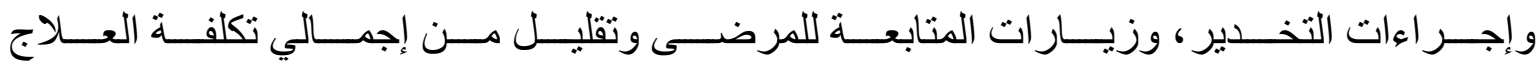
مقارنة بالميكروسكوب. 